\title{
Population Changes and Regional Policy
}

\author{
By GÖSTA OSCARSSON
}

\section{Swedish Experiences}

The connection between Swedish regional policy and demographic description of population changes will here be described with an emphasis on how the policy has changed during the last ten years and what future trends are discernable and the consequences of these changes for the demographic material needed. This choice of emphasis is partly due to the relative innocence of the referent as to the more sophisticated intricacies of demography, but is also felt to be a sensible way of utilizing the special knowledge acquired in administration. In this paper the term demography is used for the different ways of describing qualities of a population and changes in these qualities. This definition probably stretches the limits of the science, but must be chosen as any other delimitation will be beyond the competence of the referent.

The present Swedish regional policy can be said to lead its origins from a parliamentary decision in 1964. Besides the initiation of a policy for support of enterprises inside a special support area, the decision also meant the beginning of a conscious planning where the prioriting of investments in infrastructure is a central feature. In this planning the state county councils play a central role. (It could be noted that the very policy of a »decentralised national regional planning» has had special consequences for the planning methods used.) Besides having to decide on priorities on numerous specific occasions, the county councils have had two centrally initiated planning rounds - County planning 1967 and County programme 1970 - which both have been evaluated in parliamentary decisions in 1969 and 1972.

During the period since 1964 there has been a marked change of emphasis in the problem analyses and with regard to the measures proposed. The policy measures of 1964 were almost entirely concerned with the number of jobs needed for a better balance between jobs sought and offered, whereas the quality aspect of the labour market during the last years has come more and more in the forefront. Parallel with this development there has been another vital change in policy and research. From an analysis of the localization potentialities of the firm we have moved towards a discussion of the conditions essential to the living standard of the individual. 
These changes should not be stressed too heavily; the "new" aspects have more or less been present all the time. But it has of course meant a change of interest with regard to the ways in which population structure and change is measured. From a very low degree of differentiation where the interest was concentrated to net-migration and the subsequent changes in ageand sexcomposition, we are advancing towards a position where there is a need for a comprehensive mapping of the educational structure. This needs then to be matched by a picture of the structure of the local labour market. This can be seen as a heightened ambition in policy, but is perhaps more a reflection of a real change in the structure of the actual regional problems. During the sixties the country through successive educational reforms has moved a far way toward a radically different sort of labour market and during the same period the importance of the classical driving force of regional imbalances - the diminishing employment in agriculture - has become a negligible factor in most parts of the country.

We have thus reached a point where the regional problems to some extent takes in new forms and where this development stresses the need for a multivariable characterization of the population on the regional level.

In the proposition to parliament in 1972 (Prop. 1972: 111) numerous indirect ways are used to characterize the structure of the local labour markets. The share of white-collarlabour in industry and the share of the total labour force engaged in public services are there used as proxi-variables for the degree of differentiation in the labour market. An analysis of the migration has also been used. In this it is presumed that an outflow of Swedes (mostly young and with a specialised education) combined with an influx of foreign labour is a mark of a structural imbalance on a local labour market. That these indirect ways of describing the labour market have been used is to a large extent due to the complete absence of education variables in the census of 1965 and the imcomplete coverage in 1960.

The overriding importance of the labour market conditions has come out clearly in the previous paragraphs. This is also apparent from the present preparations for the next round of county planning. ${ }^{1}$ There is in this preparatory work a strong emphasis on a differentiated approach to the problems of balance on the local labour market. As far as possible the county boards shall make their prognosis for gross changes in population. (It should be noted that with a net result of the migration over-county boarders of 15.000 persons per year, there goes a gross flow of more than 200.000 persons. Radical changes in the composition of the population can thus take place even when the net movement is small. There will also be tried an analysis by sex and age for both the supply and the demand of job opportunities. From the censuses of

1 The long duration of the previous experimental round of planning - from the initiation in 1967 to the parliamentary decision in 1972 - has made an immediate revision necessary. 
1965 and 1970 it will be possible to get a picture of the structure at two given occasions. But the information about the way between one frozen picture and another is very incompletely covered by statistics. A contribution towards a clarification is the planned application of census data on migration statistics. An example of a similar application is the description of migrators by income before and after the move that is presented in the government proposal of 1972 . In similar ways the extent of interoccupational mobility must be more clearly understood. Some studies carried out under the auspices of The 1968 Educational Committee ( $U$ 68) can be taken as examples of what needs to be done; but the regionalization of a material as always requires a more total material than general surveys on the national level. ${ }^{2}$

To sum up: the ambition with regard to the next planning round is to work more in gross terms and with a more differentiated classification as to age, occupation and education. The gaps between supply and demand of job opportunities should be presented in these categories and the different ways of closing these gaps - by changes in work participation rates, in the number of commuters, in the supply of job opportunities and by change in occupation - should as far as possible be discussed for each of them. How far this ambitious program can be fulfilled is not yet clear.

If the analysis is differentiated in the way described the subsequent programmes that are based on such material will touch problems in various sectors of society. It is in this connection a fair question to ask if it is possible to formulate policies that are to a similar extent disaggregated. The experiences up till now seem to be that actions by nessecity are of a more broad and imprecise nature and that the connection with the problem analysis is of a more general nature. So has for example the difficulties to maintain a differentiated labour market outside the metropolitan areas, and the specific problems identified here, resulted in a decision to relocate central state authorities. This will work in the general direction of solving the problems identified, but will in the process create transitional problems to the people and municipalities concerned.

For more than a year the county boards have been doing preparatory studies for a new round of planning. In one project the possibilities to make a labour market prognosis for different qualification levels and educational specialities have been analysed. ${ }^{3}$ The general conclusion is, that there are some possibilities to analyse how the people wanting work are divided on specialities, whereas the structuring of the demand for labour makes so detailed prognosis from the firms necessary that this at present can be considered unrealistic. We can here see a potential connection between - in a broad sense - the personel

2 Compare SOU 1971:61 Val av utbildning och yrke and SOU 1971:62 Högre utbildning och arbetsmarknad.

3 Responsible for the study has been the county administration of Kopparbergs län. 
planning of the firm and regional planning. A development in this direction can be seen as one condition for more detailed prognosis which can prepare the ground for more specified policies. Thus there seems to be a need to descibe people with equal care as members of regional units as well as their role in the firms.

Professor Hägerstrand in a special work made for the official committee on future studies in Sweden says that the science of demography from many aspects is exemplary in describing people in a multivariable way and in avoiding the very high degree of aggregation in for instance economics. ${ }^{4}$ Nevertheless the very work of Hägerstrand - partly within the framework of ERU ${ }^{5}$ - with its great emphasis on the one scarce resource of the individual, namely time, points towards a need for new conceptual tools in regional policy and for new ways of describing people in a regional context. Here we may see the outlines of a sophisticated individual oriented method preparing the ground for new regional policies.

4 Om en konsistent individorienterad samhällsbeskrivning för framtidsstudiebruk. Justitiedepartementet Ds Ju 1972: 25.

5 Expertgruppen för regional utredningsverksamhet (the expert group for regional research). 